\title{
Huanglongbing-induced Anatomical Changes in Citrus Fibrous Root Orders
}

\author{
Naveen Kumar ${ }^{1}$ and Fnu Kiran \\ University of Maryland Eastern Shore, Princess Anne, MD 21853
}

\section{Ed Etxeberria ${ }^{1}$}

Department of Horticultural Sciences, Institute of Food and Agriculture Sciences, Citrus Research and Education Center, University of Florida, 700 Experimental Station Road, Lake Alfred, FL 33850

Additional index words. cambium, citrus greening, phloem, starch granules, xylem

\begin{abstract}
Citrus fibrous roots are vital for absorption and transport of water, nutrients, and other endogenous plant growth regulators. Efficient functioning of these roots in Huanglongbing (HLB)-affected citrus trees is important for their survival. One-year-old 'Valencia' sweet orange (Citrus sinensis L. Osbeck) trees on Swingle citrumelo were budded with HLB-infected budwood to determine the HLB-induced pathological responses at the ultrastructural level of different fibrous root orders. The fibrous root mass was dissected into four root orders: fourth-order (attached to a thick rudimentary taproot), third-order (attached to the fourth-order root), and second-order roots (attached to the third-order root). We were not able to study the ultrastructure of the first-order (attached to the second-order root) roots in this study. Severe loss in fibrous root mass was observed within 1 year following HLB infection. All root orders displayed various degrees of HLB symptoms. The fourth-order roots comprised normal phloem and disintegrated phloem. Some vascular bundles had completely disintegrated phloem tissue, whereas others showed normal ultrastructure. The fourth-order roots were also deficient in starch granules compared with controls. The pattern of phloem disintegration was similar in the third- and second-order roots. A thick layer of necrotic phloem developed near cortical cells, while the rest of the phloem structure remained normal in the third- and second-order roots. Cortical cells of both third and second orders were enriched with starch granules; therefore, soluble carbohydrates are most likely not the limiting factor for root decline in these root orders. The xylem anatomy displayed heptarch to pentarch morphology in the various root orders. These observations confirmed that various root orders in the fibrous root system are distinct and exhibit varied pathological responses during HLB pathogenesis. We propose that photosynthates deprived fourth-order roots in conjunction with necrotic phloem promoted decline in all root orders and impaired the translocation process to aboveground plant parts.
\end{abstract}

Huanglongbing (or citrus greening) has become the most devastating endemic disease in Florida, having infected $80 \%$ to $90 \%$ of commercial citrus trees (Albrigo and Stover, 2015). The disease is putatively incited by the bacterial pathogen Candidatus Liberibacter asiaticus ( $C$ Las) that is vectored by the Asian citrus psyllid (Diaphorina citri Kuwayama). Since its introduction in Florida, HLB has caused a steep decline in citrus production statewide, reaching a historical

\footnotetext{
Received for publication 8 Aug. 2017. Accepted for publication 12 Apr. 2018.

This paper is based on a presentation given during the Annual Meeting of the Florida State Horticultural Society, which was held on 4-6 June 2017, in Tampa FL.

We thank E.A. Hanlon (Soil and Water Science Department, SWFREC, IFAS, UF, Immokalee, FL 34142) and Mongi Zekri (Multi-County Citrus Agent IV, IFAS, UF, LaBelle, FL 33975) for their critical reading of this manuscript. We also thank the anonymous reviewers for their valuable comments on the manuscript.

${ }^{1}$ Corresponding authors. E-mail: fnaveenkumar@ umd.edu or eetxeber@ufl.edu.
}

low mark of 81.6 million boxes in 2016 , the lowest in the last 50 years (USDA, 2017). After introduction into host leaves, CLas travels from the point of infection to roots causing extensive injury to the fibrous root system in the process (Graham et al., 2013; Tatineni et al., 2008). Research in psyllidfree greenhouses has shown that CLas is capable of translocating from roots to shoots (Ebel, 2017). This translocation, coupled with reinoculation by psyllid vectors in commercial groves, results in uneven distribution of the bacteria (Zhong et al., 2015).

The citrus primary root system comprises woody vertical and horizontal lateral roots that provide anchorage and support, and serve as a conduit for nutrient and water transport. The smallest, subtending lateral roots are a mass of finer roots called fibrous roots (Castle and Krezdorn, 1975) that provide the bulk of water and nutrient absorption (Freeland, 2016; Noling, 2006). Most of the fibrous root mass resides within $60-75 \mathrm{~cm}$ of the soil surface (Freeland, 2016). The most commonly used citrus rootstocks in commercial groves in Florida, Carrizo citrange and $S$. citrumelo, produce extensive fibrous root systems (Castle and Krezdorn, 1975). Previous studies have established that canopy size and fruit yield of citrus trees are directly related to the fibrous root dry weight density (Castle and Youtsey, 1977; Morgan et al., 2007). Because of their finer anatomy, fibrous roots are highly susceptible to various biotic (Duncan et al., 1995; Graham et al., 2013; Tatineni et al., 2008) and abiotic (Syvertsen et al., 1983) stresses.

The precipitous decline of HLB-affected citrus trees in Florida has been directly linked to degeneration of fibrous roots (Fan et al., 2013; Graham et al., 2013). Johnson et al. (2014) demonstrated that within 10 months after infection of young 'Hamlin' trees, CLas colonized $\approx 80 \%$ of the plant roots. The HLBassociated root loss was not accompanied by ultrastructural changes in phloem anatomy, including plugging or phloem collapse, even 14 months postinoculation. Moreover, starch was present during most of the root decay period in HLB-affected trees, indicating that carbohydrates were not a limiting factor for root survival. These observations, however, are contradictory to those of Fan et al. (2013) in sweet orange 'Madam Vinous'/'Carrizo' in which, within 1 year after CLas infection, fibrous roots showed advanced stages of CLas symptoms such as phloem degeneration and starch depletion. It is likely that these discrepancies are, at least in part, outcomes of considering fibrous root mass as a single entity, whereas individual attention must be paid to distinct root orders (McCormack et al., 2015). For most of the literature on CLas-root interactions, an arbitrary cutoff of $\leq 2 \mathrm{~mm}$ diameter has been considered fibrous roots and assumed to perform similar functions (Aritua et al., 2013; Fan et al., 2013; Graham et al., 2013; Johnson et al., 2014; Zhong et al., 2015). However, this general classification of fibrous roots and sampling technique fails to explore the diversity, disease response, and functions of individual fibrous root orders in citrus as described by McCormack et al. (2015).

A thorough analysis of CLas-infected fibrous roots has not been described, with most studies focusing on a single point of interest (single vascular bundle) overlooking the adjoining anatomy (Aritua et al., 2013; Fan et al., 2013; Johnson et al., 2014; Zhong et al., 2015). Fibrous roots constitute a dynamic system in which distinct root orders perform specialized functions (McCormack et al., 2015). In citrus, fibrous root orders have different levels of plasticity for nutrient acquisition, biomass accumulation, and morphological and physiological responses during various environmental stresses (Rewald et al., 2012; Sorgona et al., 2007). Lower root orders (first and second) are characterized by their higher absorptive capacity, respiration rate, and nitrogen concentration. However, higher root orders (third and fourth) are characterized by their higher transport capacity, life span, suberin, cellulose, and total nonstructural carbohydrates (McCormack et al., 2015; Rewald et al., 2012; Sorgona et al., 2007). 


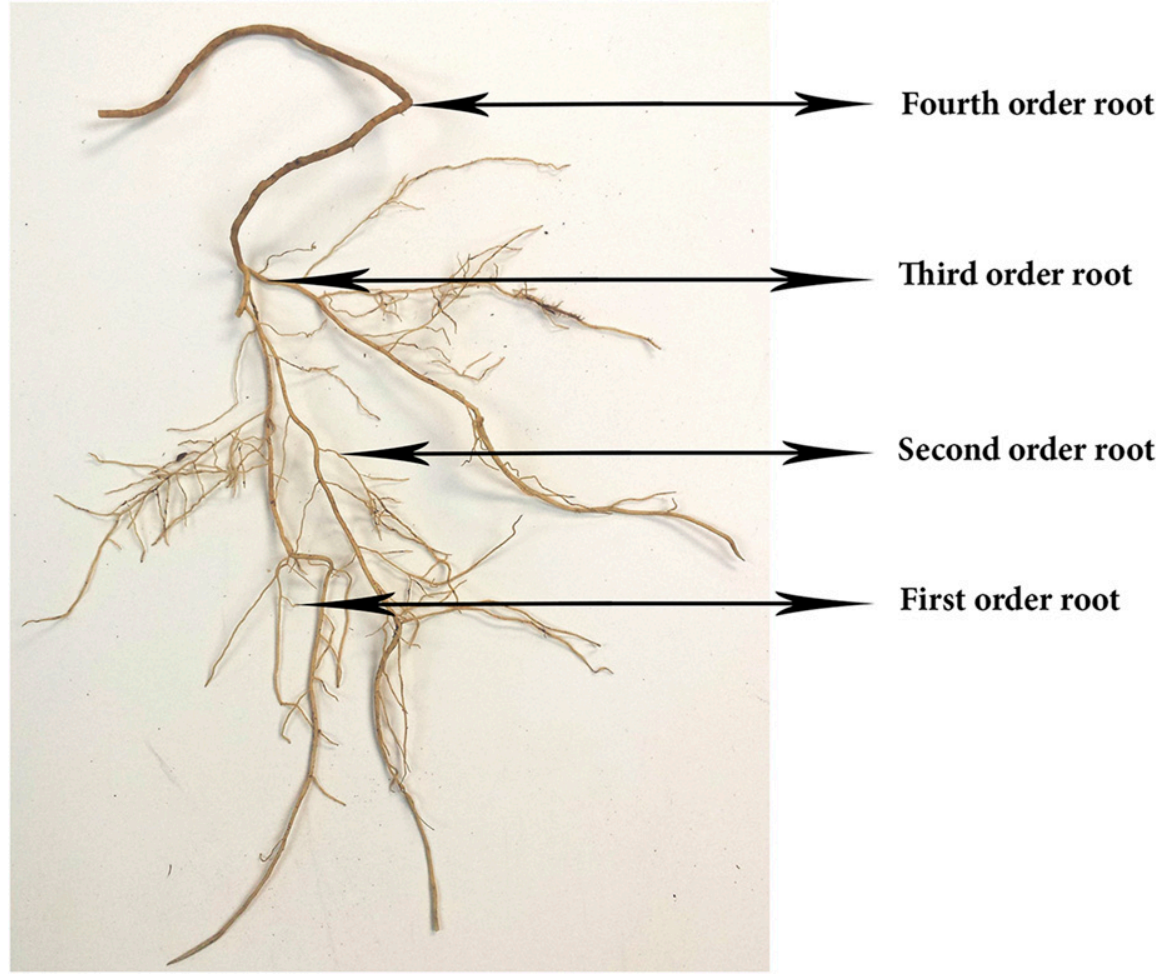

Fig. 1. Fibrous root orders in 2-year-old 'Valencia' sweet orange on Swingle citrumelo rootstock. Root orders are classified in decreasing numbers based on age and size. They also carry different physiological functions.

This work aimed at defining the dynamic changes in fibrous root anatomy and consequent collapse of phloem in HLB-infected citrus. To accomplish our goals, we sampled different root orders and evaluated the CLasinduced anatomical changes to further understand how the entire fibrous root mass collapses. Our work showed different degrees of phloem degeneration in different root orders, existence of HLB-induced vascular bundles with different levels of phloem disintegration, and distinct levels of starch granules in the cortical tissue among fibrous root orders. This work revealed the significance of individual root orders in the overall process of root collapse of HLB-affected citrus trees.

\section{Materials and Methods}

Plant material and culture. One-year-old 'Valencia' sweet orange $(C$. sinensis L. Osbeck) trees on $S$. citrumelo were purchased from a commercial nursery (Phillip Ruck Citrus Nursery, Lake Wales, FL) and maintained in 3-gallon plastic pots containing Miracle-Gro potting mixture (Marysville, $\mathrm{OH})$ in a psyllid-free greenhouse. Mineral nutrition was provided at 3-month intervals using "Citrus Gain" (8:3:9) fertilizer (Bougainvillea Growers International, St. James City, FL). The trees were graft inoculated with HLB-affected buds obtained from 11-year-old HLB-affected sweet orange 'Valencia' trees from groves at the Citrus Research and Education Center, Lake Alfred, FL. One year after grafting, the trees showed characteristic symptoms of HLB. Mature leaves had yellow mottling, corky leaf veins, stunting, and twig dieback. Young leaves remained small and had interveinal and veinal chlorosis, and excessive leaf drop. The trees were in evident decline.

Root sampling and tissue preparation for $S E M$. Three replications of root samples were randomly selected per pot 1 year after inoculation from seven HLB-infected and an equal number of healthy control trees. Potting medium was removed from the pots with a gentle water wash and roots were sampled from three different sectors of the root zone. Fibrous root orders were classified into four orders. First-order (first) roots subtended second-order (second), second-order subtended third-order (third), and third-order subtended fourth-order roots (fourth), which are finally subtended by the thick rudimentary taproot (Fig. 1). Different fibrous root orders (second-, third-, and fourth-order fibrous roots) were dissected. The root tissue by order were transferred to chilled $100 \%$ ethanol for $2 \mathrm{~h}$. The root samples were then sectioned and stored for $48 \mathrm{~h}$ in $100 \%$ ethanol. The ethanol solution was refreshed after $24 \mathrm{~h}$. The root samples were further dehydrated using a Ladd 28000 critical point dryer (Ladd Research Industries, Burlington, VT), subsequently mounted on a stub, and coated with gold/palladium using a Ladd 30800 sputter coater (Ladd Research Industries). Coated tissue samples were observed using a Hitachi S530 SEM (Tokyo, Japan) and photographed using a Cannon Rebel T5i digital camera (Tokyo, Japan).

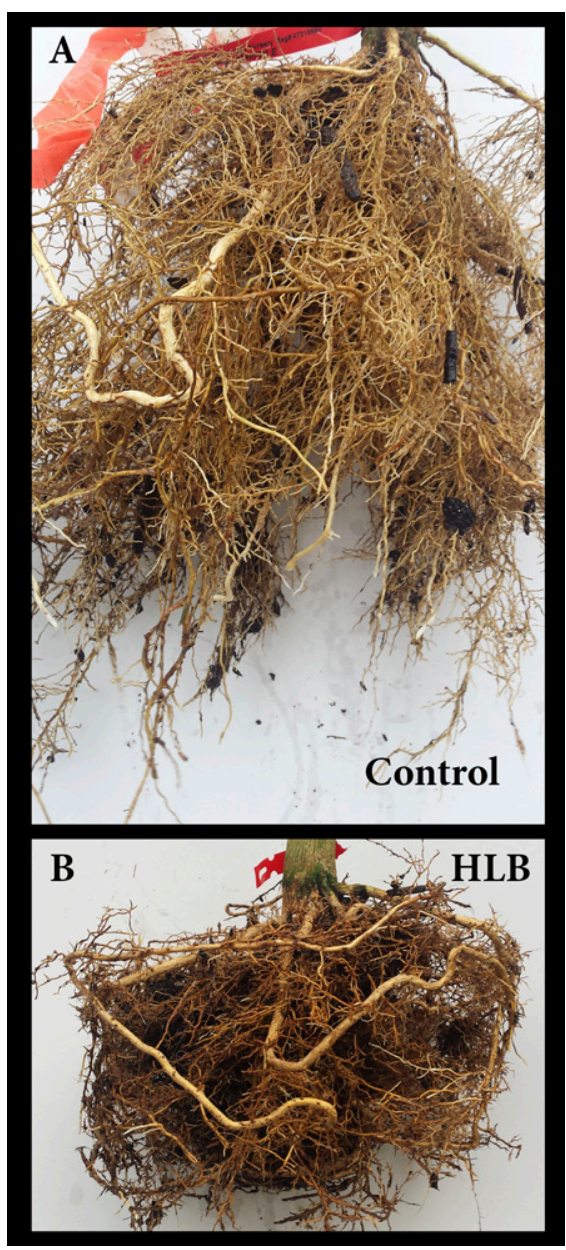

Fig. 2. Fibrous roots of 2-year-old 'Valencia' sweet orange trees on Swingle citrumelo rootstock. (A) Roots from a Huanglongbing (HLB)-uninfected control tree showing abundance of second- and third-order roots. (B) Root mass of a 2-year-old HLB-infected tree (1 year after infection) showing the loss of second- and third-order roots. Note the color contrast between the two.

Three sections per root sample were analyzed. Total root replications were 63 [7 (pots) $\times 3$ (roots per pot $) \times 3($ section per root $)=63$ ] Thickness of vessel wall, lumen, and starch granules were measured on randomly selected 10 vessels and 10 starch granules per section from both HLB-affected and control trees. A total of 21 randomly selected sections were used from seven trees each from HLB-affected and control trees. Vessels near the phloem tissue (protoxylem) and pith (metaxylem) were measured in this study. The $2 \times$ SE was calculated.

\section{Results}

Fibrous root morphology. Four fibrous root orders were observed in 2-year-old healthy 'Valencia' sweet orange $(C$. sinensis L. Osbeck) trees on rootstock $S$. citrumelo. The diameter of roots within various root orders declined from the fourth order to the first order [fourth: $1.2( \pm 0.01) \mathrm{mm}$; third: 0.6 $( \pm 0.02) \mathrm{mm}$; second: $0.5( \pm 0.01) \mathrm{mm}$; first: $0.5( \pm 0.1) \mathrm{mm}]$ as would be expected 


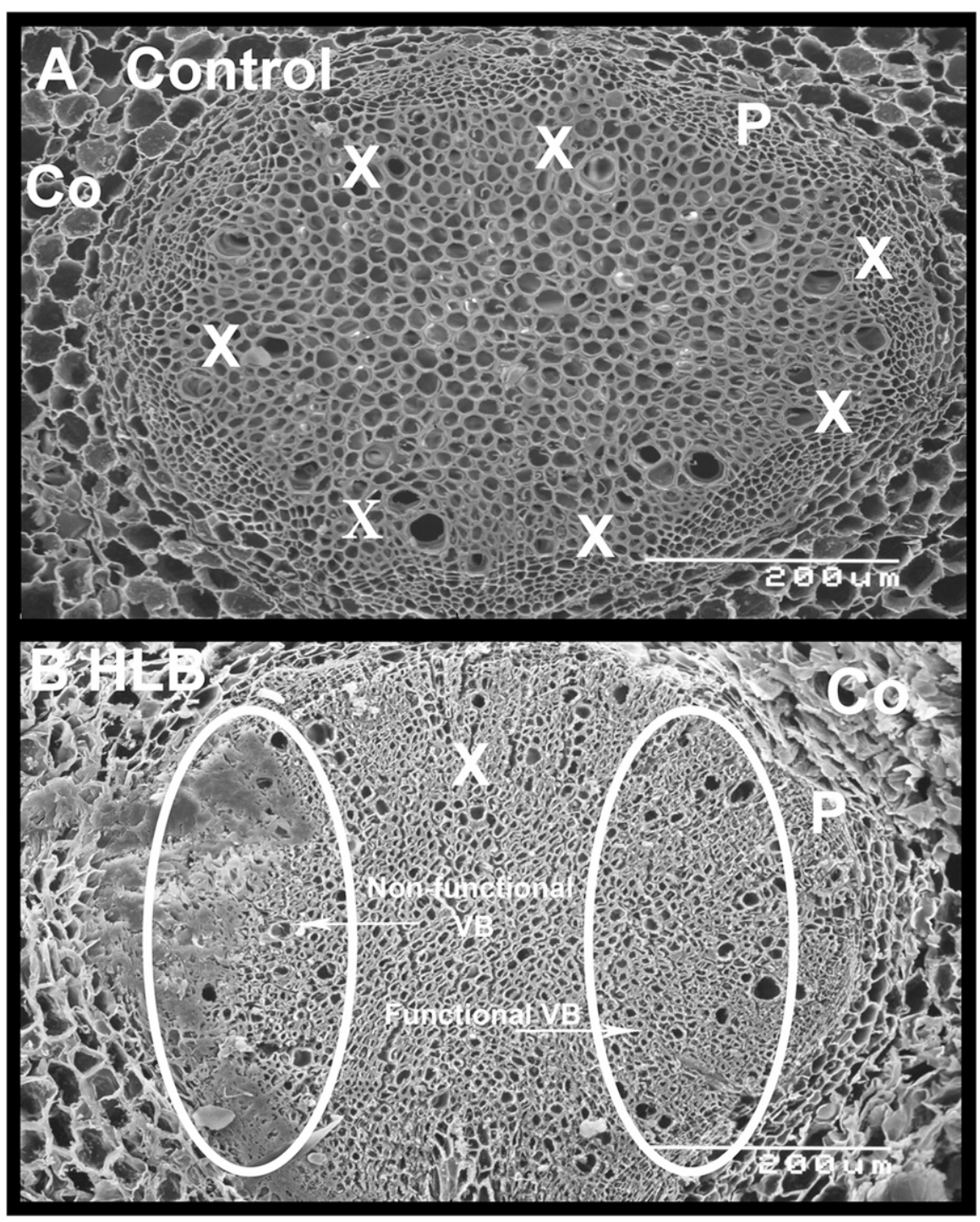

Fig. 3. Scanning electron micrograph of a transverse section of a fourth-order fibrous root of 2-year-old 'Valencia' sweet orange trees on Swingle citrumelo rootstock. (A) Vascular stele from a control Huanglongbing (HLB)-free root. (B) Vascular stele of an HLB-infected root showing partially damaged phloem tissue. Tissue plugging extends to the xylem. $\mathrm{X}=\mathrm{xylem} ; \mathrm{P}=$ phloem; Co $=$ cortex. because of age/time of development. We were not able to obtain workable sections of first-order roots because of their very small size; therefore, the anatomy of first-order roots was not evaluated in this work.

A dense fibrous root mass was evident in healthy control trees (Fig. 2A). However, in all the HLB-affected trees, a significant loss in fibrous root mass was evident a year after infection (Fig. 2B). Healthy trees also showed new root growth, whereas very little new root growth was observed in HLB affected tress. Fibrous roots appeared black to dark brown in color in diseased trees and light brown in healthy controls (Figs. 1 and $2 \mathrm{~A}$ and $\mathrm{B}$ ).

Internal anatomy by fibrous root order. The fourth-order fibrous roots consisted of fusing or fused heptarch vascular bundles as shown in Fig. 3. In healthy root samples, merging vascular bundles contained healthy and functional phloem and xylem tissue (Fig. 3A). The cells had smooth edges and contained little or no cellular debris. Phloem cells were clearly distinguishable into sieve elements and companion cells (Fig. 4A). By contrast, HLB-affected roots had an unhealthy/injured appearance often with plugged phloem tissue (Figs. 3B and 4B). Moreover, it became evident that throughout fourth-order fibrous roots, protoxylem vessel walls of HLB-affected roots were $63 \%$ and metaxylem walls were $17 \%$ thicker (protoxylem: $3.1 \pm 0.1 \mu \mathrm{m}$; metaxylem: $2.1 \pm 0.1 \mu \mathrm{m})$ and the size of the lumen in protoxylem averaged $76 \%$ and metaxylem averaged $24 \%$ (protoxylem: $6.2 \pm 0.6 \mu \mathrm{m}$; metaxylem: $7.5 \pm$ $0.4 \mu \mathrm{m})$ smaller than that in the healthy controls (vessel thickness: protoxylem: $1.9 \pm$ $0.1 \mu \mathrm{m}$, metaxylem: $1.8 \pm 0.1 \mu \mathrm{m}$; vessel lumen: protoxylem: $13.9 \pm 0.9 \mu \mathrm{m}$, metaxylem: $20.7 \pm 0.6 \mu \mathrm{m}$ ) (Fig. 3A). Phloem cells were completely crushed in some HLBaffected trees (Figs. 3B and 4B). Nevertheless, some vascular tissue still appeared normal and functional without any substantial

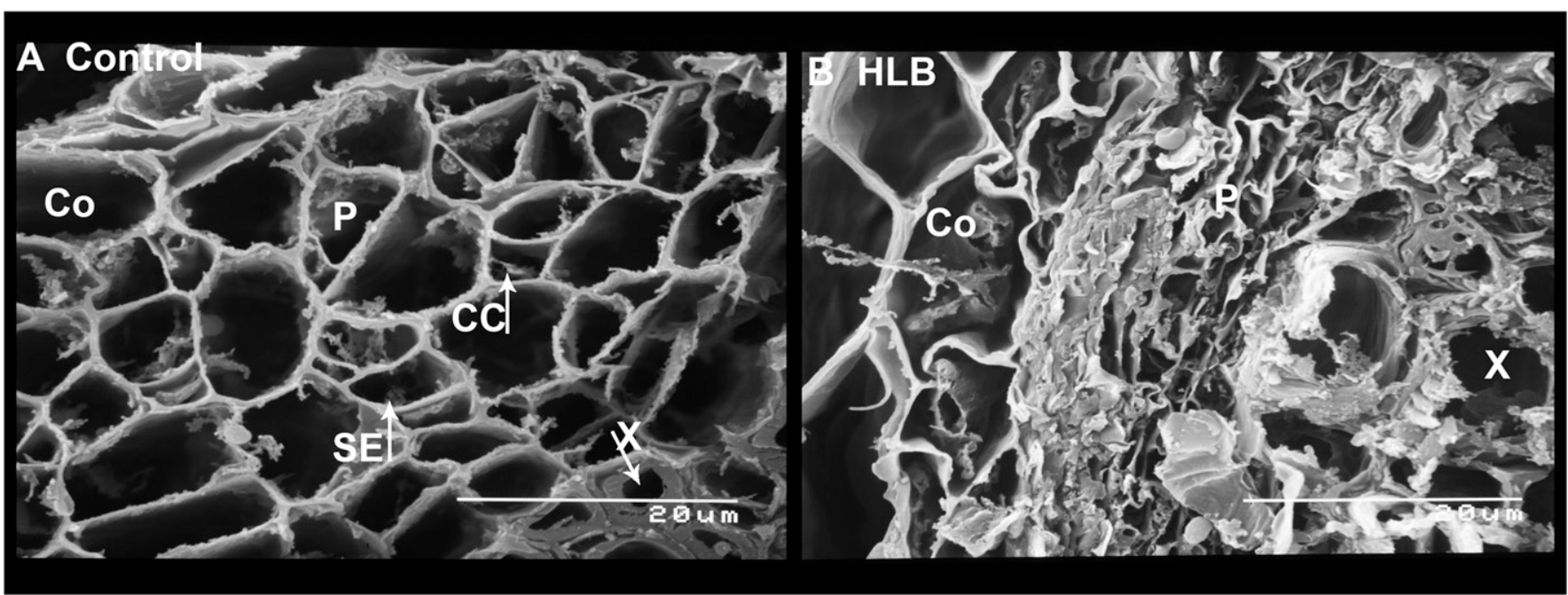

Fig. 4. Scanning electron micrograph of a transverse section of fourth-order fibrous roots of 2-year-old 'Valencia' sweet orange trees on Swingle citrumelo rootstock. (A) Close up of phloem tissue from control Huanglongbing (HLB)-free roots. (B) Close up of phloem tissue of HLB-infected roots. X $=$ xylem; $\mathrm{P}=$ phloem; $\mathrm{Co}=$ cortex $; \mathrm{Ca}=$ cambium; $\mathrm{SE}=$ sieve element $\mathrm{CC}=$ companion cell. 
ultrastructural changes (Fig. 3B). This is consistent with compartmentalization of $C$ Las within the plant and indicates that the effects of HLB are localized to within individual sieve tubes and perhaps vascular bundles (Ebel, 2017). These results showed the existence of normal and disintegrated phloem in vascular bundles of CLasinfected fourth-order fibrous roots. Cortical cells of healthy roots were loaded with starch grains (diameter: $4.7 \pm 0.2 \mu \mathrm{m}$ ), whereas the same types of cells in CLas-infected roots were completely devoid of starch granules (Fig. 5A and B).

The third-order fibrous roots were characterized by radial anatomy with xylem and phloem alternating on different radii on the axis and heptarch anatomy of vascular bundles (Fig. 6). Phloem and xylem tissue were normal in healthy roots, but showed signs of phloem degeneration and compression in HLB-affected roots (Fig. 7A and B). Phloem appeared as a mass of partially compressed tissue adjoining cortical cells in HLBaffected roots. The remaining parts of phloem tissue were occluded with starch grains and swollen cell walls. Cortical cells were enriched with starch grains in both control (diameter: $2.5 \pm 0.3 \mu \mathrm{m}$ ) and HLB-affected third-order fibrous roots (diameter: $4.6 \pm 0.2 \mu \mathrm{m}$ ) (Fig. 8A and B). However, the size of starch grains was $84 \%$ larger in HLB-affected thirdorder fibrous roots in comparison with the controls.

The second-order root vascular bundles were characterized by radial and pentarch anatomy of vascular bundles (Fig. 9A and B). Five xylem bundles alternate with five phloem bundles in both control and HLBaffected roots. Phloem ultrastructure was similar to that observed in the third-order roots. No phloem degeneration was observed in control roots (Fig. 10A). However, phloem tissue showed early signs of degeneration near cortical cells and thickening of the xylem vessels in HLB-affected roots (Fig. 10B). Furthermore, phloem tissue showed extensive cytoplasmic accumulations. Cortical cells were enriched with starch reserves in both control (diameter: $1.5 \pm 0.1 \mu \mathrm{m}$ ) and CLasinfected (diameter: $1.5 \pm 0.3 \mu \mathrm{m}$ ) roots (Fig. 11A and B).

\section{Discussion}

In recent years, HLB has caused severe decline in citrus production in Florida and threatens the very survival of the citrus industry (USDA, 2017). The decline in tree health and productivity has been partially attributed to CLas-induced loss of fibrous roots, which also results in increased susceptibility to other biotic and abiotic stresses (Graham et al., 2013). Our work provides a clearer picture of CLas infection in citrus roots and the corresponding ultrastructural changes in different fibrous root orders. In our investigation, visual observation showed severe decline in fibrous roots in all trees within 1 year following CLas infection in psyllid-free greenhouse-grown potted sweet

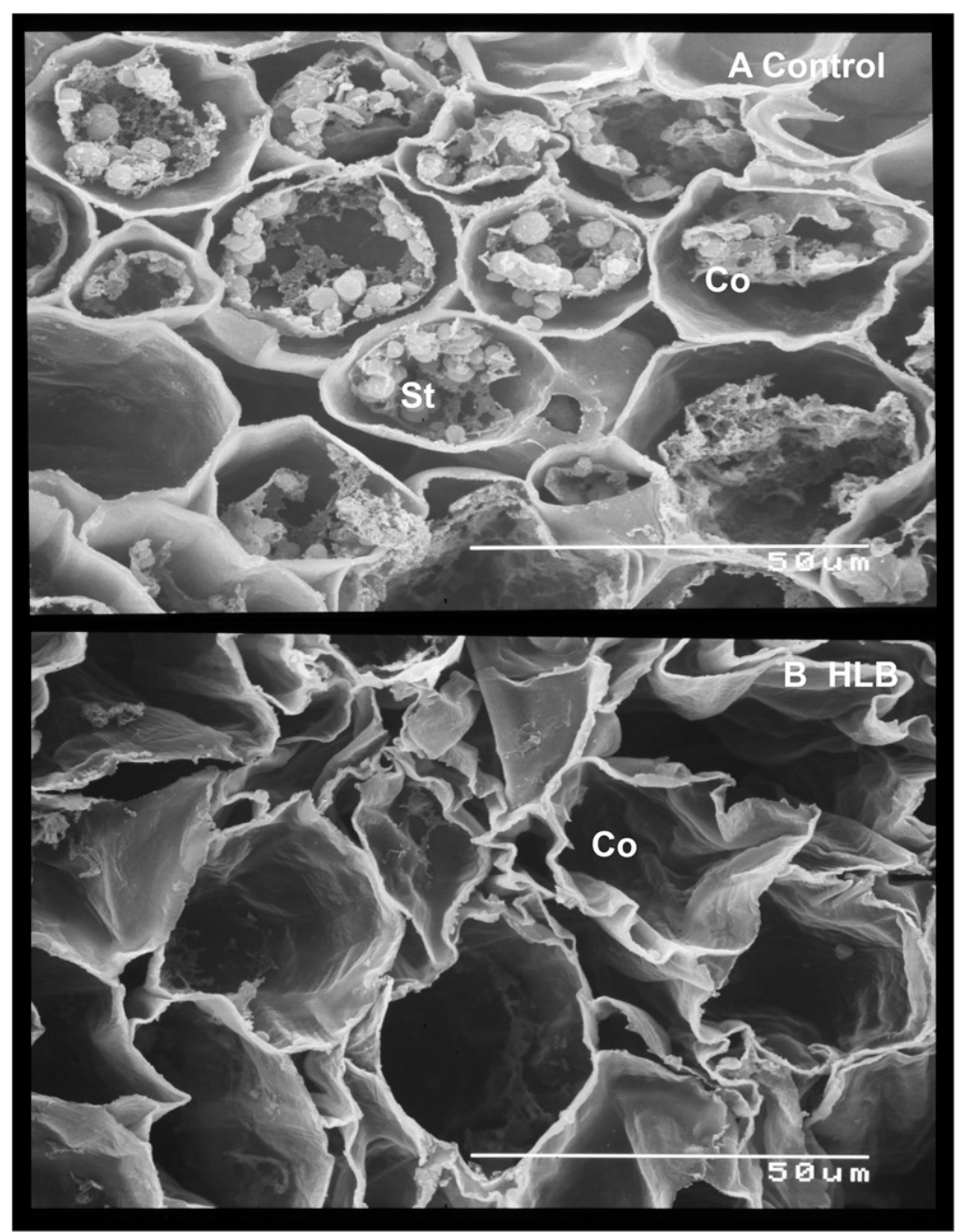

Fig. 5. Scanning electron micrograph of a transverse section of fourth-order root in fibrous roots showing the cortical region of 2-year-old 'Valencia' sweet orange trees. (A) Cortex from a Huanglongbing (HLB)-free control tree. (B) Cortex of an HLB-infected tree. Note the stark contrast in starch content. $\mathrm{Co}=$ cortex; $\mathrm{St}=$ starch grains.

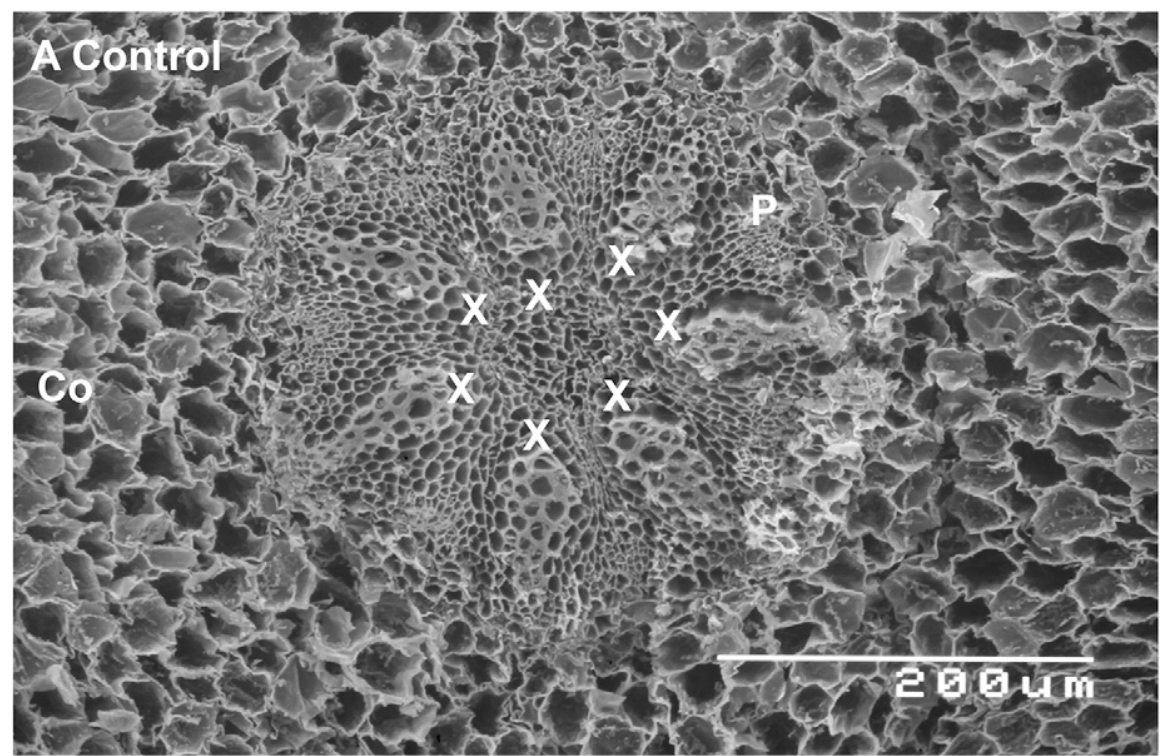

Fig. 6. Scanning electron micrograph of a transverse section of third-order root in fibrous roots of Huanglongbing-free, 2-year-old 'Valencia' sweet orange trees on Swingle citrumelo rootstock. The figure depicts a heptarch vascular bundle. $\mathrm{X}=\mathrm{xylem} ; \mathrm{P}=$ phloem; $\mathrm{Co}=$ cortex. 


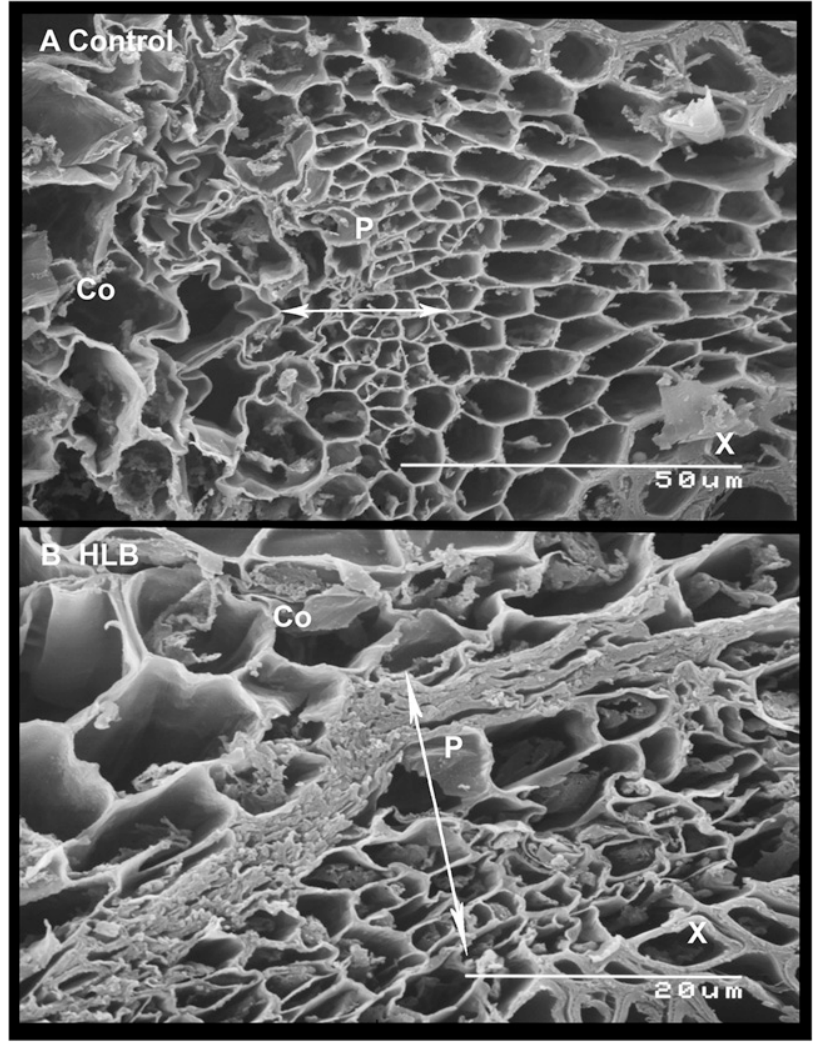

Fig. 7. Scanning electron micrograph of a transverse section of third-order root in fibrous roots of 2-yearold 'Valencia' sweet orange trees on Swingle citrumelo rootstock. (A) Phloem from a control tree showing functional phloem. (B) Phloem from a Huanglongbing-infected tree contains a band of dead/ crushed protophloem. $\mathrm{X}=$ xylem; $\mathrm{P}=$ phloem; $\mathrm{Co}=$ cortex .

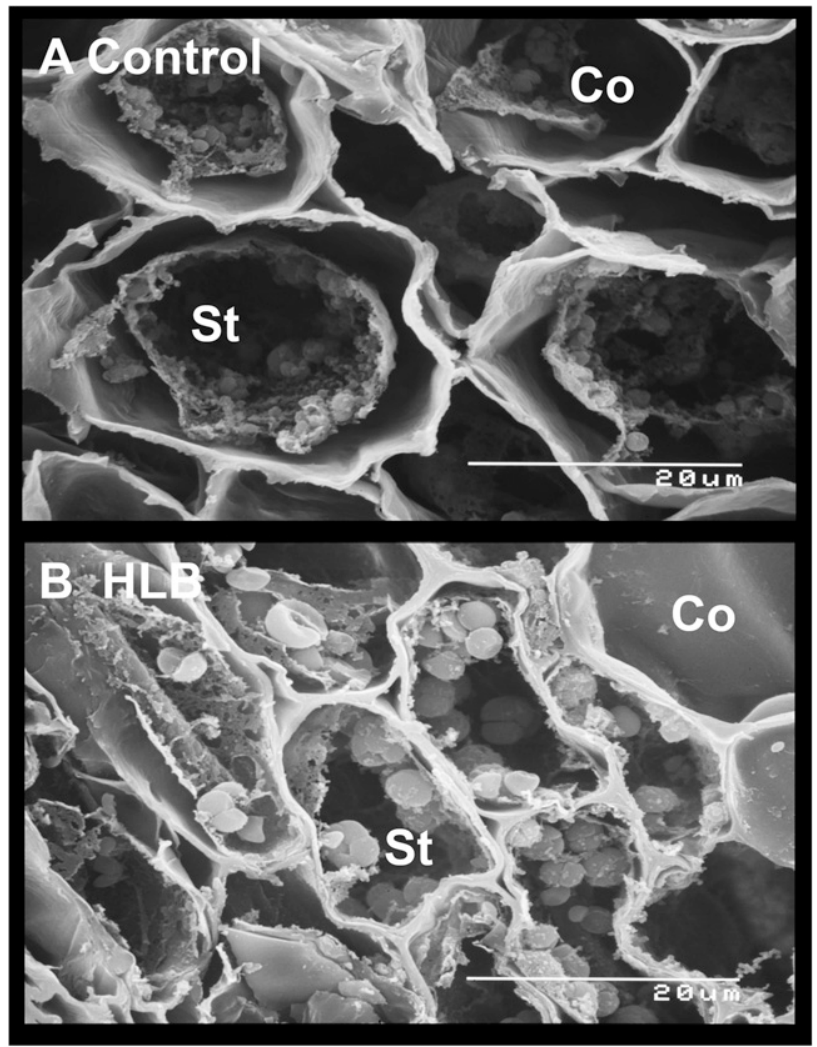

Fig. 8. Scanning electron micrograph of a transverse section of third-order fibrous roots showing the cortical region of 2-year-old 'Valencia' sweet orange trees on Swingle citrumelo rootstock. (A) Root cortex from a Huanglongbing (HLB)-free control tree. (B) Root cortex from an HLB-infected tree. $\mathrm{Co}=$ cortex; $\mathrm{St}=$ starch grains . orange 'Valencia' trees (Fig. 2B). Fibrous root mass in HLB-affected trees were spongy and black to dark brown in color, possibly due to higher peroxidase levels, detected in CLas-infected roots, a condition that promotes polymerization of lignin and tannin resulting in tissue browning of roots (Lavid et al., 2001; Zhong et al., 2015). The lignified brown-colored fibrous roots not only act as a barrier against pathogen invasion, but also cause significant decline in root absorptive capacity, thus making plants susceptible to water stress (Duncan et al., 1993). The decline in root mass function partly explains why CLas-infected citrus trees are more vulnerable to water and high temperature stress (Johnson and Graham, 2015).

There are four root orders in 'Valencia' sweet orange ( $C$. sinensis L. Osbeck) trees on $S$. citrumelo, all vulnerable to $C$ Las infection (Figs. 1 and 2B). In most current anatomical, physiological, pathological, and molecular evaluations, the entire fibrous root mass has been considered as one indistinguishable organ (Aritua et al., 2013; Fan et al., 2013; Graham et al., 2013; Johnson et al., 2014; Zhong et al., 2015). Therefore, little information is available regarding the effect of HLB on different root orders, especially in various citrus rootstocks. Eight root orders were reported in Citrus volkameriana irrigated with fresh water, whereas only seven exist when irrigated with saline water (Rewald et al., 2012). However, only three root orders were observed in Poncirus trifoliata L. and Citrus jambhiri Lush (Eissenstat and Achor, 1999; Rewald et al., 2012). Root orders in citrus have distinct morphology, anatomy, and physiology (Rewald et al., 2012; Sorgona et al., 2007; Wells and Eissenstat, 2003). Higher order roots are older and thicker than lower order roots, which reflects the division of labor (Fig. 2). The thicker higher root orders (fourth) are adapted to transport support functions, whereas absorption is predominantly governed by lower root orders (second; Eissenstat and Achor, 1999). The thickness of fibrous root orders has been positively correlated with root longevity (Wells and Eissenstat, 1997). Regardless of the order, all root orders are highly susceptible to HLB (Fig. 1B)

The fourth-order fibrous roots in this study were considered as roots subtending on lateral roots (Fig. 1). The HLB-affected roots were characterized by the presence of normal phloem and disintegrated phloem (Fig. 3B). Part of the phloem tissue in these HLB-affected trees was crushed, blocked, and degenerated, but appeared healthy or normal in other parts. According to Ebel (2017), crushing and degeneration of sieve cells in HLB-affected tree marked, in part, the diversion of lignin precursors for the synthesis of antimicrobial compounds (scopoletin), rendering the sieve wall weak and vulnerable to the pressure generated by newly formed phloem. The different phloem organization in vascular bundles suggests the progression of HLB symptoms in roots. 


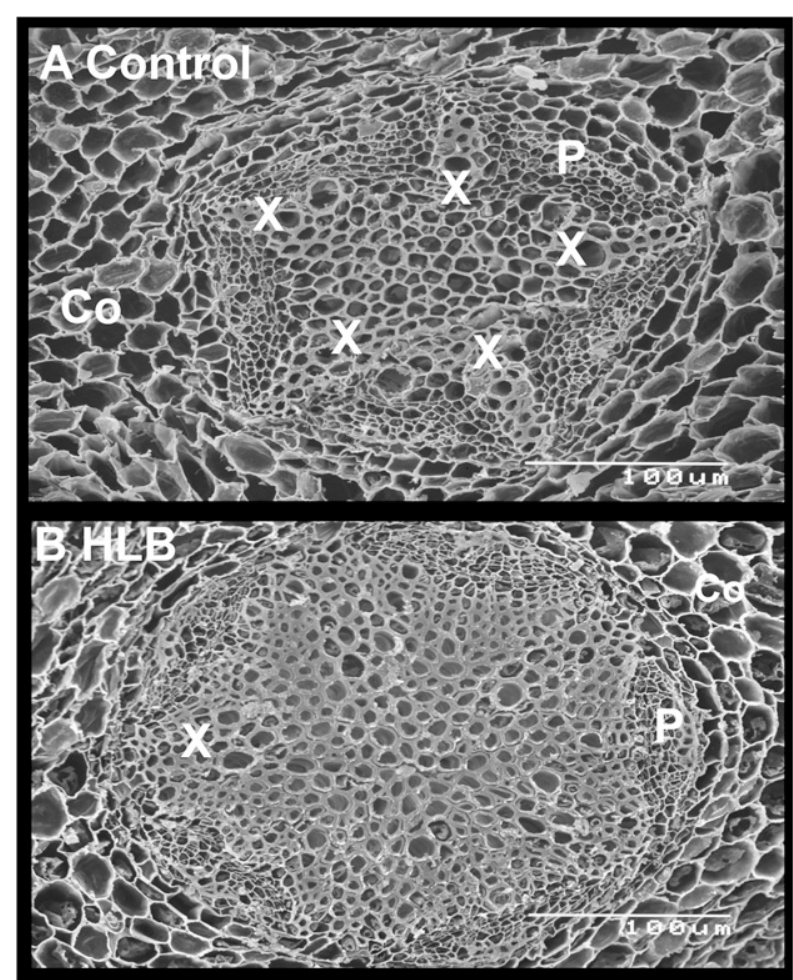

Fig. 9. Scanning electron micrograph of a transverse section of second-order root in fibrous roots of 2-yearold 'Valencia' sweet orange trees on Swingle citrumelo rootstock. (A) Root from a control tree showing a healthy vascular stele. (B) Root from a Huanglongbing-infected tree. $\mathrm{X}=$ xylem; $\mathrm{P}=$ phloem; $\mathrm{Co}=$ cortex

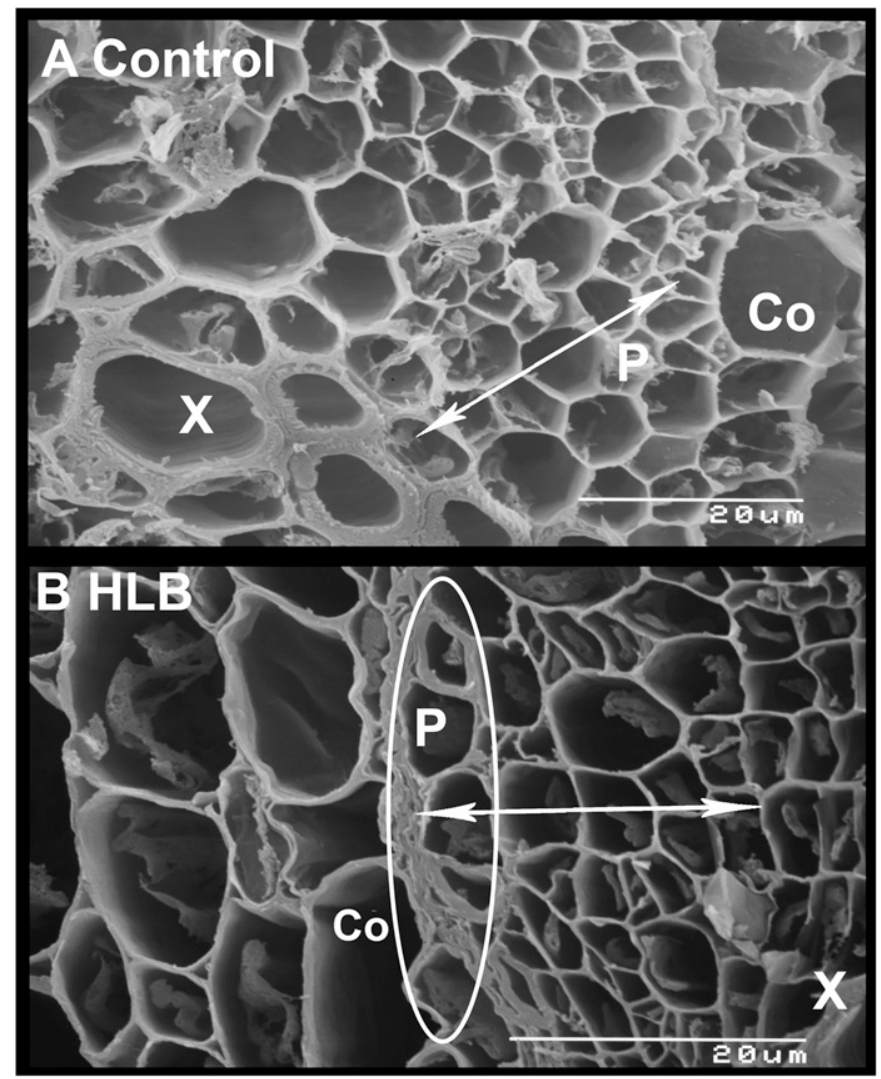

Fig. 10. Scanning electron micrograph of a transverse section of second-order root in fibrous roots of 2-year-old 'Valencia' sweet orange trees on Swingle citrumelo rootstock. (A) Vasculature in the root of a control tree. (B) Vascular tissue in the root of a Huanglongbing-infected tree. $\mathrm{X}=\mathrm{xylem}$; $\mathrm{P}=$ phloem; $\mathrm{Co}=$ cortex
Furthermore, the fourth-order fibrous roots remained partly functional, which would support rhizosphere function in CLasinfected roots. Our results differ from those reported by Johnson et al. (2014) in sweet orange 'Hamlin' on 'Swingle' citrumelo rootstock, where no signs of phloem blockage were documented in fibrous roots 10 months after CLas infection. An additional sign of HLB's effect on root function was the lack of starch granules, whereas copious amounts of starch granules were present in uninfected roots. It seems HLB-affected fourth-order roots developed a sustainable strategy for carbon partitioning toward lower order (third and second) roots to sustain the absorption of water and nutrients while simultaneously maintaining the transport function despite some phloem damage (Eissenstat and Achor, 1999). The fourth-order roots and other higher order roots are a more permanent part of the root organization, whereas lower order roots have a higher turnover rate (Valenzuela-Estrada et al., 2008). Contrary to this normal observation in healthy trees, HLB-induced starch partitioning toward lower root orders might jeopardize the survival of fourth-order roots, which supports lower order roots. It seems that HLB-induced starch deprivation, limited photosynthate supply, and phloem abnormality over a period of 1 year lead to a decline in fourth-order roots and concomitant disintegration of lower order fibrous roots. Root development is the outcome of a complex transcriptional network which fluctuates spatiotemporally in individual roots and indicates the existence of variability in gene expression in different roots and in different tissue of the same root (Brady et al., 2007). Based on our anatomical observations, higher levels of starch accumulation in lower root orders (Figs. 8B and 11B) can be the outcome of HLB-induced acceleration in the rate of starch synthesis (Zhong et al., 2015), and alternatively young roots (second and third order) act as a strong sink in comparison with older roots (fourth order; McCormack et al., 2015). There is evidence that showed a higher expression of starch synthase and ADP-glucose pyrophosphorylase in HLB-affected roots (Zhong et al., $2015)$. In addition, suppression of $\beta$-amylase 3 (which converts amylopectin into maltose), $\beta$-amylase 6 , and sucrose synthase 3 (which converts sucrose into uridine diphosphate glucose and fructose) has been also observed in these roots (Zhong et al., 2015). Both observations support the accumulation of starch and inhibition of its degradation in lower order roots as evidenced from our anatomical observations (Figs. 8B and 11B). This evidence also rules out the recycling of soluble sugars from second- and third-order roots to fourth-order roots. Even though no change in $\alpha$-amylase (which converts amylose into glucose) expression was reported in this study (Zhong et al., 2015), we expect that steady levels of $\alpha$-amylase activity were maintained which successively recycled the glucose moieties for starch synthesis in second- and third-order roots 


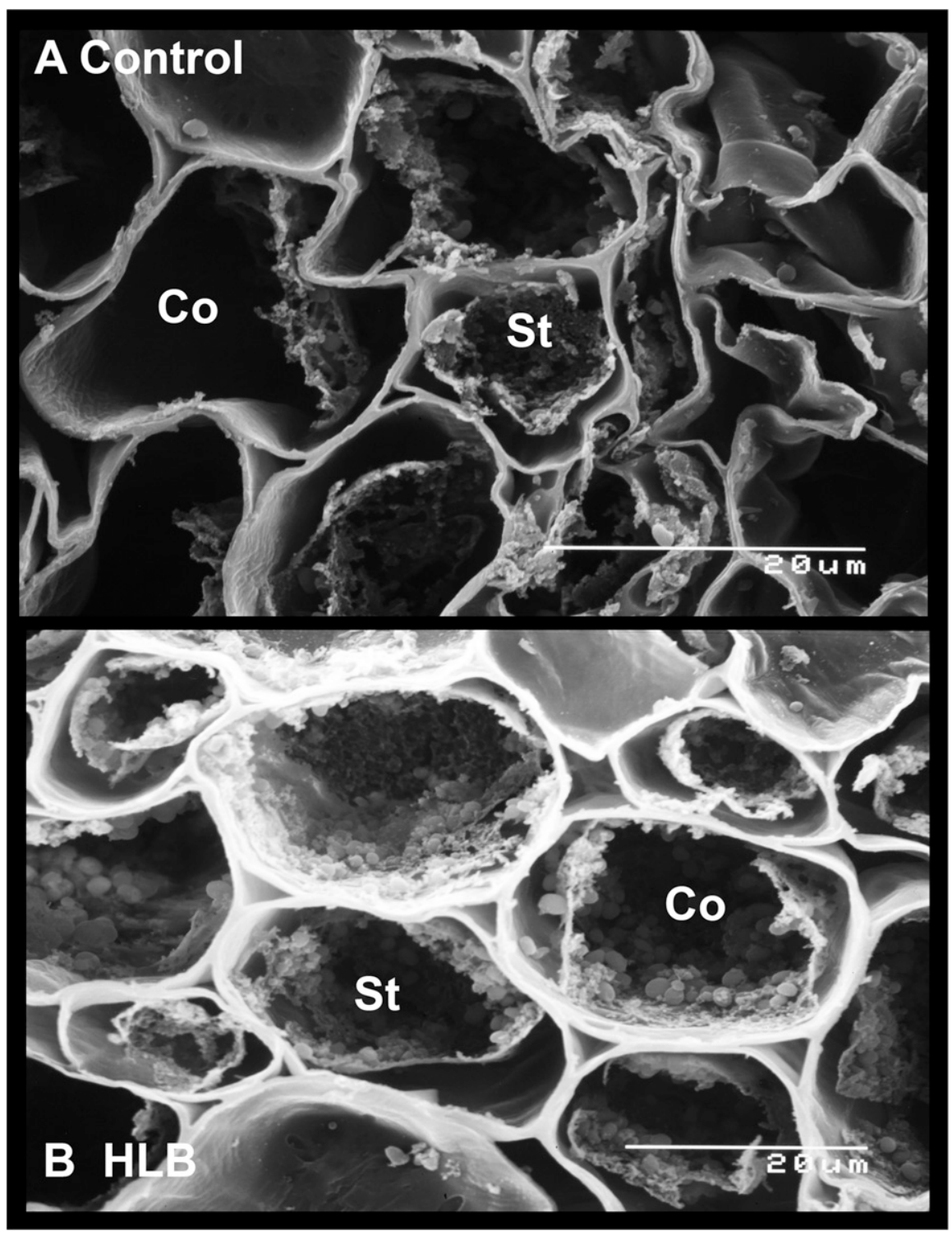

Fig. 11. Scanning electron micrograph of a transverse section of second-order root in fibrous roots showing the cortical region of 2-year-old 'Valencia' sweet orange trees on Swingle citrumelo rootstock. (A) Root cortex of a Huanglongbing (HLB)-free control tree. (B) Root cortex of an HLB-infected tree. $\mathrm{Co}=$ cortex; $\mathrm{St}=$ starch grains.

(Ebel, 2017). Higher invertases (which convert sucrose into glucose and fructose) expression was observed in HLB-affected roots, but the mobility of these sugars is further hindered by the degenerating phloem, swelling of middle lamellae, and separation of individual cells from each other (Figs. 3B, 4B, 7B, and B10B; Aritua et al., 2013). The alternative hypothesis for decline in fourthorder roots may be the extreme parasitism by CLas (Ebel, 2017) as higher CLas abundances were reported in horizontal roots $(96 \%)$ near the soil surface in comparison with deep vertical roots $(78 \%)$ in HLB-affected trees (Louzada et al., 2016).

The ultrastructure of third-order fibrous roots revealed the existence of seven xylem bundles (heptarch condition), with five xylem bundles (pentarch) in second-order fibrous roots (Figs. 6 and 9). Eissenstat and Achor characteristic initial symptoms of HLB. Interestingly, cortical cells in both control and HLB-affected roots were loaded with starch granules (Fig. 8A and B). These observations are a clear indication that phloem necrosis and photosynthate limitation are two different and independent pathological consequences of HLB in roots of citrus. Otherwise, degenerating phloem tissue in stem, petiole, leaf midveins, and fourth-order roots may impose photosynthate limitation in lower order roots (third and second; Fig. 11B; Etxeberria et al., 2009; Fan et al., 2013). However, no such observation was documented in our study at this stage of development. Alternatively, this finding also suggests the coexistence of alternative pathways of photosynthate transport in addition to phloem in HLB-affected plant tissue (Brodersen et al., 2014).

Phloem breakdown in second-order fibrous roots was similar to that in third-order roots with cell swelling and phloem necrosis near cortical cells (Fig. 10B). The cell walls were swollen and sieve elements showed cytoplasmic aggregates. Swelling of the middle lamella is a characteristic ultrastructural feature in HLB-affected plants (Aritua et al., 2013; Ebel, 2017). It has been shown that pectin synthesis is downregulated and its catabolism is upregulated in HLB-affected plant tissue including roots (Albrecht and Bowman, 2008; Ebel, 2017; Zhong et al., 2015). By-products of pectin disintegration with exposed hydroxyl groups attract water molecules and impart cell swelling (Ebel, 2017), which could also interfere with normal functioning of plasmodesmata and, thus, restrict nutrient and assimilate transport and promote cell necrosis. This hypothesis is further strengthened by the separation of adjacent phloem cells in HLB-affected root tissue in sweet orange 'Valencia' (Aritua et al., 2013; Kumar et al., 2014).

Phloem abnormality in second-order roots confirmed the impact of HLB in very young roots, and it has been shown that the lower root orders have a very short life span of $\approx 95-105 \mathrm{~d}$ for first-order roots and 226 $259 \mathrm{~d}$ for second-order roots (Wells and Eissenstat, 2003). HLB further lowered this life span as evident from the significant loss of roots within 1 year after CLas infection (Fig. 2). From the observations presented in this study, root collapse in citrus trees does not commence from the youngest roots and proceed to the more mature roots, but instead, root collapse of fibrous roots results from carbon starvation brought about by phloem degeneration of higher root levels. As reported by Johnson et al. (2014), root decline precedes starch accumulation in aerial parts, a condition that would similarly affect the younger roots. Our data refine the chronological sequence of root decline after HLB infection.

Phloem degeneration is a characteristic symptom observed in all the root orders following CLas infection. This anatomical anomaly can also interfere with the hydraulic nexus between phloem and xylem tissue 
(Pfautsch et al., 2015). In addition to photosynthate translocation, phloem tissue also acts as a capacitor of water and solutes and mediates water transport to xylem during higher hydraulic tensions in xylem vessels (Pfautsch et al., 2015; Zwieniecki et al., 2004). Girdling experiments were conducted to mimic the symptoms of HLB in citrus (Cimo et al., 2013; Liao and Burns, 2012). There is a $15 \%$ to $24 \%$ decline in xylem hydraulic conductance following girdling in stems of Acer saccharum Marsh and Acer rubrum L., respectively. Similarly, our visual observations in HLB-affected fourth-order roots showed that $>50 \%$ of the phloem tissue is blocked, disorganized, and degenerated (Figs. 3B and 4B), which can also reduce xylem hydraulic conductance and promote water deficits. This conclusion is supported by the work of Hamido et al. (2017), who found a significant decline in stem water potential (healthy: $-0.9 \mathrm{MPa}$; HLB: -1.2 $\mathrm{MPa}$ ) and sap flow (healthy: $38.6 \mathrm{~g} \cdot \mathrm{m}^{-2} \cdot \mathrm{h}^{-1}$; HLB: $16.9 \mathrm{~g} \cdot \mathrm{m}^{-2} \cdot \mathrm{h}^{-1}$ ) with a concomitant higher total available soil water (healthy: 83\%; HLB: 95\%) in HLB-affected sweet orange 'Valencia'. We expect that necrotic phloem tissue in various root orders lose the hydraulic nexus with xylem and impair xylem functioning in HLB-affected trees. Moreover, our novel observation in the fourth-order roots showed highly thickened protoxylem $(3.1 \pm 0.1 \mu \mathrm{m})$ and metaxylem $(2.1 \pm 0.1 \mu \mathrm{m})$ walls, which are $63 \%$ and $17 \%$ thicker in comparison with healthy trees. In addition, there is a gradient of thickness in xylem walls across proto- and metaxylem tissue in HLB-affected fourth-order roots (Figs. 3B and 4B). Protoxylem walls are $32 \%$ thicker than metaxylem walls. Vessel thickness was also associated with subsequent decline in lumen diameter in HLBaffected fourth-order roots (Fig. 3A and B). This decline was $55 \%$ in protoxylem and $64 \%$ in metaxylem in comparison with lumen diameter in healthy roots. These observations suggest impairment of water transport in addition to phloem malfunction in HLBaffected trees. Further studies are required to confirm the hypothesis in which phloem anomaly can also impair xylem functioning in the roots and other plant parts of HLB-affected trees.

\section{Conclusions}

Based on the anatomical observations, we propose the following cascade of deteriorative events occurring in different root orders within 1 year after $C$ Las infection in 'Valencia' sweet orange (C. sinensis L. Osbeck) trees on S. citrumelo: I: Phloem disintegration and starch depletion occurred at a higher rate in fourth-order roots; II: Phloem disintegration in lower root orders; III: Photosynthates deprived the collapse of fourth-order roots and concomitant decline in other lower root orders; and IV: Decrease in the size of xylem lumen and increase in wall thickness that severely affect water transport.

\section{Literature Cited}

Albrecht, U. and K.D. Bowman. 2008. Gene expression in Citrus sinensis (L). Osbeck following infection with the bacterial pathogen 'Candidatus Liberibacter asiaticus' causing huanglongbing. Plant Sci. 175:291-306.

Albrigo, L.G. and E.W. Stover. 2015. Effect of plant growth regulators and fungicides on huanglongbing-related preharvest fruit drop of citrus. HortTechnology 25:785-790.

Aritua, V., D. Achor, F.G. Gmitter, Jr., G. Albrigo, and N. Wang. 2013. Transcriptional and microscopic analyses of citrus stem and root responses to Candidatus Liberibacter asiaticus infection. PLoS One 8(9):1-12.

Brady, S.M., D.A. Orlando, J-Y. Lee, J.Y. Wang, J. Koch, J.R. Dinneny, D. Mace, U. Ohler, and P.N. Benfey. 2007. A high-resolution root spatiotemporal map reveals dominant expression patterns. Science 318(2):801-806.

Brodersen, C., C. Narciso, M. Reed, and E. Etxeberria. 2014. Phloem production in huanglongbing-affected citrus trees. HortScience 49:59-64.

Castle, W.S. and A.H. Krezdorn. 1975. Effect of citrus rootstocks on root distribution and leaf mineral content of 'Orlando' tangelo tree. J. Amer. Soc. Hort. Sci. 100:1-4.

Castle, W.S. and C.O. Youtsey. 1977. Root system characteristics of citrus nursery trees. Proc. Annu. Mtg. Fla. State Hort. Soc. 90:39-44.

Cimo, G., R.L. Biano, P. Gonzalez, W. Bandaranayake, E. Etxeberria, and J.P. Syvertsen. 2013. Carbohydrate and nutritional responses to stem girdling and drought stress with respect to understanding symptoms of huanglongbing in citrus. HortScience 48:920-928.

Duncan, L.W., J.H. Graham, and L.W. Timmer. 1993. Seasonal pattern associated with Tylenchulus semipenetrans and Phytophthora parasitica in the citrus rhizosphere. Phytopathology 83:573-581.

Duncan, L.W., P. Mashela, J. Ferguson, J. Graham, M.M. Abou-Setta, and M.M. El-Morshedy. 1995. Estimating crop loss in orchards with patches of mature citrus tree infected by Tylenchulus semipenetrans. Nematropica 25:4351.

Ebel, R.C. 2017. Huanglongbing: Mechanism of citrus decline and horticulture management in Florida. Integrated Plant Health Services, LLC, Fort Myers, FL.

Eissenstat, D.M. and D.S. Achor. 1999. Anatomical characteristics of roots of citrus rootstocks that vary in specific root length. New Phytol. 141:309-321.

Etxeberria, E., P. Gonzalez, D.S. Achor, and G. Albrigo. 2009. Anatomical distribution of abnormally high levels of starch in HLB-affected Valencia orange trees. Physiol. Mol. Plant Pathol. 74:76-83.

Fan, J., C. Chen, D.S. Achor, R.H. Brlansky, Z-G. Li, and F.G. Gmitter, Jr. 2013. Differential anatomical responses of tolerant and susceptible citrus species to the infection of Candidatus Liberibacter asiaticus. Physiol. Mol. Plant Pathol. 83:69-74.

Freeland, R.S. 2016. Surveying the near-surface fibrous citrus root system of the orange tree with 3-D GPR. Appl. Eng. Agr. 32:145-153.

Graham, J.H., E.F. Johnson, T.R. Gottwald, and M.S. Irey. 2013. Pre-symptomatic fibrous root decline in citrus trees caused by huanglongbing and potential interaction with Phytophthora spp. Plant Dis. 97:1195-1199.

Hamido, S.A., K.T. Morgan, and D.M. Kadyampakeni. 2017. The effect of huanglongbing on young citrus tree water use. HortTechnology 27:659665.

Johnson, E.G. and J.H. Graham. 2015. Root health in the age of HLB. Citrus Ind. 98:14-18.

Johnson, E.G., J. Wu, D.B. Bright, and J.H. Graham. 2014. Association of Candidatus Liberibacter asiaticus root infection, but not phloem plugging with root loss on huanglongbing-affected trees prior to appearance of foliar symptoms. Plant Pathol. 63:290-298.

Kumar, N., C. Brodersen, C. Narciso, and E. Etxeberria. 2014. Enzyme digestion of HLBinfected tissue: A better approach to study phloem anatomy. Proc. Fla. State Hort. Soc. 127:33-36.

Lavid, N., A. Schwartz, O. Yarden, and E. Tel-Or. 2001. The involvement of polyphenols and peroxidase activities in heavy-metal accumulation by epidermal glands of the waterlily (Nymphaeaceae). Planta 212:323-331.

Liao, H-L. and J.K. Burns. 2012. Gene expression in Citrus sinensis fruit tissues harvested from huanglongbing-infected tress: Comparison with girdled fruit. J. Expt. Bot. 63(8):33073319.

Louzada, E.S., O. Ed. Vazquez, W.E. Braswell, G. Yanev, M. Devanaboina, and M. Kunta. 2016. Distribution of Candidatus Liberibacter asiaticus above and below ground in Texas citrus. Phytopathology 106(7):702709.

McCormack, M.L., I.A. Dickie, D.M. Eissenstat, T.J. Fahey, C.W. Fernandez, D. Guo, H-S. Helmisaari, E.A. Hobbie, C.M. Iversen, R.B. Jackson, J. Leppalammi-Kujansuu, R.J. Norby, R.P. Phillips, K.S. Pregitzer, S.G. Pritchard, B. Rewald, and M. Zadworny. 2015. Redefining fine roots improves understanding of belowground contributions to terrestrial biosphere processes. New Phytol. 207:505-518.

Morgan, K.T., T.A. Obreza, and J.M.S. Scholberg. 2007. Orange tree fibrous root length distribution in space and time. J. Amer. Soc. Hort. Sci. 132:262-269.

Noling, J.W. 2006. Citrus root growth and soil pest management practices. Citrus Veg. Mag. 55:12-18.

Pfautsch, S., J. Renard, M.G. Tjoelker, and A. Salih. 2015. Phloem as capacitor: Radial transfer of water into xylem of tree stem occurs via symplastic transport in ray parenchyma. Plant Physiol. 167:963-971.

Rewald, B., E. Raveh, T. Gendler, J.E. Ephrath, and S. Rachmilevitch. 2012. Phenotypic plasticity and water flux rates of citrus root orders under salinity. J. Expt. Bot. 63:27172727.

Sorgona, A., M.R. Abenavoli, P.G. Gringeri, and G. Cacco. 2007. Comparing morphological plasticity of root orders in slow and fast growing citrus rootstocks supplied with different nitrate levels. Ann. Bot. 100:12871296.

Syvertsen, J.P., R.M. Zablotowicz, and M.L. Smith, Jr. 1983. Soil temperature and flooding effects on two species of citrus. Plant Soil 72:312.

Tatineni, S., U.S. Sagaram, S. Gowda, C.J. Robertson, W.O. Dawson, T. Iwanami, and N. Wang. 2008. In planta distribution of Candidatus Liberibacter asiaticus as reveled by polymerase chain reaction (PCR) and real-time PCR. Phytopathology 98:592-599.

USDA. 2017. Citrus fruit summary. USDA, NASS $1-35$.

Valenzuela-Estrada, L.R., V. Vera-Caraballo, L.E. Ruth, and D.M. Eissenstat. 2008. Root anatomy, morphology, and longevity among root orders in 
Vaccinium corymbosum (Ericaceae). Amer. J. Bot. 95:1506-1514.

Wells, C.E. and D.M. Eissenstat. 1997. Diameter and pigmentation affect fine root survivorship in apple. Bull. Ecol. Soc. Amer. 78:205.

Wells, C.E. and D.M. Eissenstat. 2003. Beyond the roots of young seedlings: The influence of age and order on fine root physiology. J. Plant Growth Regul. 21:324-334.

Zhong, Y., C-Z. Cheng, N-H. Jiang, B. Jiang, Y-Y. Zhang, B. Wu, M-L. Hu, J-W. Zeng, H-X. Yan, G-J. Yi, and G-Y. Zhong. 2015. Comparative transcriptome and iTRAQ proteome analysis of citrus root responses to Candidatus
Liberibacter asiaticus infection. PLoS One 10(6): $1-21$.

Zwieniecki, M.A., P.J. Melcher, T.S. Field, and N.M. Holbrook. 2004. A potential role for xylemphloem interactions in the hydraulic architecture of trees: Effects of phloem girdling on xylem hydraulic conductance. Tree Physiol. 24:911-917. 